\title{
Intraperitoneal magnesium sulphate plus bupivacaine for pain relief after laparoscopic cholecystectomy
}

Maharjan SK', Shrestha S ${ }^{2}$

${ }^{1}$ Associate Professor, ${ }^{2}$ Assistant Professor, Department of Anaesthesiology and Intensive Care Kathmandu Medical College, Sinamangal, Kathmandu

\section{Abstract}

Background: Multimodal analgesia is necessary for management of pain after laparoscopic cholecystectomy. Magnesium sulphate is a new emerging drug for management of acute pain. This study was performed to study the analgesic efficacy of intraperitoneal bupivacaine and bupivacaine plus magnesium sulphate for postoperative pain relief after laparoscopic cholecystectomy.

Methods: At the end of laparoscopic cholecystectomy, 60 patients were randomized to one of the following groups: bupivacaine group receiving intraperitoneal instillation of $30 \mathrm{ml}$ of $0.25 \%$ bupivacaine and magnesium sulphate group receiving intraperitoneal instillation of $0.25 \%$ bupivacaine plus $50 \mathrm{mg} / \mathrm{kg}$ magnesium sulphate to total volume of $30 \mathrm{ml}$. Postoperative pain was evaluated by using visual analogue scale (standard Visual Analogue Scale pain score of 0-10). Time duration of first analgesia demanded was noted and rescue analgesic was given as tramadol 50 mg intravenously and on demand. Pain, Visual Analogue Scale score and total analgesic consumption was recorded for 24 hours and analysed. Results: The patients who were given intraperitoneal bupivacaine plus magnesium sulphate at the end of surgery had better pain relief in first 24 hours, Visual Analogue Scale score of 0-5 compared to sole bupivacaine group who had Visual Analogue Scale score of 3-7. The magnesium sulphate group had longer pain free period of average $5.53 \pm 4.33$ hours after surgery compared to $3.16 \pm 1.59$ hours in sole bupivacaine group. Total analgesic consumption in magnesium sulphate group was also less compared to bupivacaine group (125.0 \pm 36.5 and $75.0 \pm 25.0$ in bupivacaine and magnesium sulphate group respectively). All the results show highly significant differences between the groups.

Conclusion: The combined instillation of bupivacaine and magnesium sulphate into the peritoneal cavity at the end of laparoscopic surgery renders patients better pain control and less consumption of analgesics in first 24 hours compared to sole bupivacaine group.

Key words: Bupivacaine, Laparoscopic cholecystectomy, Magnesium sulphate, Post-operative analgesia.

\section{Introduction}

A $s$ laparoscopic surgeries are gaining popularity, different modalities of perioperative pain management are being used. Apart from the parenteral route of analgesic use, intraperitoneal instillation of local anaesthetics and opioids are gaining popularity for better pain relief'. Administration of magnesium sulphate via different routes has been used in anaesthetic practice for decreasing perioperative pain. Parenteral magnesium sulphate has been used

\footnotetext{
Address for correspondence

Dr. Shyam Krishna Maharjan

Associate Professor

Department of Anaesthesiology and Intensive Care

Kathmandu Medical College

E-mail: shyammaharjan2@hotmail.com
}

for many years as an antiarrhythmic agent and for seizure prophylaxis in eclampsia and preeclampsia. It is $\mathrm{N}$-methyl $\mathrm{d}$-aspartate (NMDA) receptor antagonist and suppresses these receptor induced inflammation and hyper responsiveness ${ }^{2}$.

The antinociceptive effect of magnesium sulphate is not only useful in chronic pain, but it also determines in part, the duration and intensity of postoperative pain ${ }^{2}$. These effects are due to calcium antagonism and decrease influx of calcium into the cell and antagonism of NMDA receptor. As these receptors regulate neuronal signalling and are involved in pain processing, magnesium sulphate by blocking this receptor, decreases postoperative pain as well ${ }^{3,4}$. 
Different studies have shown that magnesium sulphate is useful in chronic as well as in acute pain management. We combined magnesium sulphate with bupivacaine to study the analgesic efficacy of intraperitoneal magnesium sulphate for pain relief after laparoscopic cholecystectomy.

\section{Materials and methods}

This is a prospective, randomized, double blind study done in Kathmandu Medical College, in six months' time period. Randomization was done with envelop method and data collection and analysis was done by another anaesthesiologist not involved in delivering anaesthesia. After institutional approval and obtaining informed consent, 60 patients of American Society of Anaesthesiologists (ASA) physical status I and II were taken for study. Both male and females patients of 18-65 years were randomly divided into two groups of 30 each to be administered one of the following intraperitoneal instillations: "bupivacaine group" received $30 \mathrm{ml}$ of $0.25 \%$ bupivacaine not exceeding the dose $2.0 \mathrm{mg} / \mathrm{kg}$ and "magnesium sulphate group" $0.25 \%$ bupivacaine 30 $\mathrm{ml}$ along with $50 \mathrm{mg} / \mathrm{kg}$ of magnesium sulphate.

All patients were educated about the standard Visual Analogue Scale (VAS) pain score of 0-10, during preanaesthetic evaluation visit. Patients with allergy to study drugs, magnesium sulphate and bupivacaine, heart block and renal failure and those with peritoneal drain after surgery were excluded from the study. All study drugs were prepared by the anaesthesiologist not involved in the study and data collection. All patients were premedicated with metoclopramide, ranitidine and diazepam, the evening before surgery.

On arrival to the operating room, intravenous line was opened and standard ASA recommended monitoring established. General anaesthesia was induced with intravenous lignocaine $1.0 \mathrm{mg} / \mathrm{kg}$, fentanyl 2.0 microgram $/ \mathrm{kg}$ and propofol $2.0 \mathrm{mg} / \mathrm{kg}$. Vecuronium $0.1 \mathrm{mg} / \mathrm{kg}$ was used to facilitate endotracheal intubation. Anaesthesia was maintained with halothane, 50\% oxygen in air and positive pressure ventilation. At the end of surgery, study drugs were instilled into the peritoneal cavity. After reversing the residual effect of vecuronium with neostigmine and glycopyrrolate and with adequate respiratory efforts, trachea was extubated and patients were transferred to postoperative ward when they were fully awake and responding to vocal commands.

Visual analogue scale (VAS) pain score was recorded in first, second, fourth, sixth, eighth, twelfth and twenty fourth hours after surgery. Time duration of first demand for analgesia and total tramadol consumption in 24 hours were recorded. $50 \mathrm{mg}$ intravenous tramadol was given as rescue analgesic on demand as well to assess the analgesic efficacy of study drugs. Regular use of analgesic drug may mask the actual effect of the study drugs; therefore we used the analgesics on demand only. We used VAS pain score of zero to ten to assess the pain score. Zero for no pain; score of one, two and three for mild pain; four, five, six and seven for moderate pain; and eight, nine and ten for severe pain.

Sample size calculation was done from previous study results assuming that reduction of 3.0 relative to control value in mean post-operative pain score would be detectable using sample size of 30 patients per group for analysis of variance (ANOVA) analysis with $80 \%$ power and alpha level of 0.05 . Statistical analysis was done with SPSS for windows version 15. Significance test was done with independent samples t-test. Results displayed as mean \pm standard deviation and $p$ value less than 0.05 was taken as significant.

\section{Results}

Patient characteristics regarding age, gender and weight were comparable in the two groups. There was no significant difference between the groups regarding duration of anaesthesia and surgery as well (table 1).

When we analysed the VAS score seven times in 24 hours; after one, two, four, six, eight, twelve and twenty four hours of surgery; the cumulative mean pain score was less in magnesium sulphate group compared to sole bupivacaine group and the difference was statistically significant $(p<0.05)$. In first hour bupivacaine group had VAS pain score of $3.47 \pm 2.96$ and magnesium sulphate group had score of $1.70 \pm 1.86$. Similarly the bupivacaine group had higher VAS pain score in 2 - 24 hours compared to magnesium sulphate group $(3.87 \pm 2.76-2.20 \pm 1.85$ and $2.47 \pm 1.17-1.77 \pm 0.85$ respectively) (table 2 ).

The average time interval of first analgesia demand was also longer in magnesium sulphate plus bupivacaine group compared to sole bupivacaine group $(5.53 \pm 4.33$ hours compared to $3.16 \pm 1.59$ hours respectively) which was also highly significant. When total analgesia consumption in 24 hours was analysed, bupivacaine group had $125 \mathrm{mg}$ and magnesium sulphate group had $75 \mathrm{mg}$ of tramadol consumption which was statistically significant (table 3). Bupivacaine group had mild to moderate pain and most of the patients in bupivacaine plus magnesium sulphate group had mild pain in first 24 hours of surgery. 
Table 1: Patient's demographic characteristics and duration of anaesthesia and surgery.

\begin{tabular}{lccc}
\hline Age: years(Mean \pm Standard deviation, SD) & Bupivacaine group & $\begin{array}{c}\text { Bupivacaine +Magnesium } \\
\text { sulphate group }\end{array}$ & $\begin{array}{c}\text { P-value } \\
\mathbf{3 5 . 1 7} \pm \mathbf{1 5 . 5 1}\end{array}$ \\
$\begin{array}{l}\text { Gender: } \\
\text { Female: Male }\end{array}$ & $\mathbf{3 9 . 8 0 \pm 1 3 . 1 7}$ & $27: 3$ \\
\hline $\begin{array}{l}\text { Weight: Kg (mean } \pm \text { Standard Deviation) } \\
\text { Duration of Anaesthesia: minutes (mean } \pm \text { SD) }\end{array}$ & $54.83 \pm 8.45$ & $53.47 \pm 11.82$ & 0.341 \\
\hline $\begin{array}{l}\text { Duration of surgery: } \\
\text { minutes (mean } \pm \text { SD) }\end{array}$ & $48.73 \pm 14.06$ & $54.10 \pm 33.00$ & 0.231 \\
\hline
\end{tabular}

Table 2: VAS pain score in different time intervals in the two groups (mean \pm standard deviation).

\begin{tabular}{|cccc}
\hline Time interval & Bupivacaine group & Bupivacaine + Magnesium group & p-value \\
\hline $1^{\text {st }}$ hour & $3.47 \pm 2.96$ & $1.70 \pm 1.86$ & 0.000 \\
$2^{\text {nd }}$ hour & $3.87 \pm 2.76$ & $2.47 \pm 1.17$ & 0.019 \\
$4^{\text {th }}$ hour & $4.93 \pm 2.99$ & $1.97 \pm 1.08$ & 0.000 \\
$6^{\text {th }}$ hour & $2.97 \pm 2.58$ & $2.10 \pm 1.42$ & 0.000 \\
$8^{\text {th }}$ hour & $2.73 \pm 1.18$ & $1.93 \pm 1.79$ & 0.001 \\
$12^{\text {th }}$ hour & $2.97 \pm 2.81$ & $2.23 \pm 1.76$ & 0.002 \\
$2^{\text {th }}$ hour & $2.20 \pm 1.85$ & $1.77 \pm 0.85$ & 0.000 \\
\hline VAS score in range $\ln 24 \mathrm{hrs}$ & $3-7$ & $0-5$ &
\end{tabular}

Table 3: First analgesic demanded time and total analgesic consumption in 24 hours (mean \pm standard deviation)

\begin{tabular}{lccc}
\hline Group & Bupivacaine group & Bupivacaine+ magnesium sulphate group & p-value \\
\hline Time of 1st analgesic(hours) & $3.16 \pm 1.59$ & $5.53 \pm 4.33$ & 0.000 \\
\hline $95 \%$ confidence interval & Lower: 2.560 & Lower: 3.814 \\
& Upper: 3.7664 & Upper: 7.143 \\
\hline Total tramadol in 24 hours $(\mathrm{mg})$ & $125.0 \pm 36.5$ & $75.0 \pm 25.0$ \\
\hline $95 \%$ confidence interval & Lower:86.0 & Lower:60.5 \\
\hline
\end{tabular}

\section{Discussion}

In this study, we analysed the analgesic effect of intraperitoneal instillation of magnesium sulphate with bupivacaine in patients undergoing laparoscopic cholecystectomy. Our results showed that addition of magnesium sulphate to bupivacaine decreases postoperative pain and analgesic consumption in first 24 hours after surgery along with longer pain free period compared to patients who were given sole bupivacaine after laparoscopic cholecystectomy. Longer pain free period and less analgesic requirements may be due to blockage of both somatic and visceral pain fibres.

As magnesium decreases intracellular calcium influx and also antagonizes NMDA receptor thereby decreasing postoperative pain, it is useful for decreasing somatic and visceral pain. It can be used parenterally as bolus and as continuous infusion for perioperative pain management and to decrease the opioid analgesic requirements as well ${ }^{5,6,16}$.

As pain after laparoscopic surgery is multifactorial and multimodal analgesia is necessary to counter this pain and parenteral as well as intraperitoneal magnesium sulphate may be useful in this regard. We used $50 \mathrm{mg} / \mathrm{kg}$ of magnesium sulphate for intraperitoneal instillation. There are various described doses of parenteral use of $50 \mathrm{mg} / \mathrm{kg}$ bolus and the continuous infusion till end of surgery, and one report of use of $30 \mathrm{mg} / \mathrm{kg}$ of intraperitoneal magnesium sulphate $\mathrm{e}^{7,8,9,17,18}$. 
Abdel Rouf and Amer $\mathrm{H}$ studied the postoperative analgesic effects of intraperitoneal NMDA receptor antagonist, magnesium sulphate and ketamine in patients undergoing laparoscopic cholecystectomy. They used $30 \mathrm{mg} / \mathrm{kg}$ of magnesium sulphate in patients receiving intraperitoneal $0.25 \%$ bupivacaine and 1 $\mathrm{mg} / \mathrm{kg}$ of ketamine along with $0.25 \%$ bupivacaine and concluded that demand for first analgesia in NMDA receptor antagonist was around 130 minutes after surgery compared to control and bupivacaine group (15.30 minutes and 35.30 minutes respectively) $)^{7}$. Our study also shows $2-5$ hours of less pain period in patients with intraperitoneal instillation of bupivacaine and magnesium sulphate.

Lee Kim et al reported that incisional and intraperitoneal bupivacaine is effective in decreasing somatic pain during first three postoperative hours ${ }^{10}$. Hernandez et al investigated the intraperitoneal application of bupivacaine plus morphine for pain relief after laparoscopic surgery and reported that combination is effective in decreasing pain during first 6 hours ${ }^{1}$. Our study also shows bupivacaine and magnesium sulphate renders patients pain free period of 2-5 hours and tramadol consumption is also less compared to sole bupivacaine group.

Tamer MR et al studied the perioperative intravenous bolus and infusion of magnesium sulphate and concluded that it is associated with smaller analgesic requirements, less discomfort and better quality of sleep in the postoperative period but with no adverse effects ${ }^{11}$. Edmunds $S$ et al reported that when magnesium sulphate was used as an adjunct for anaesthesia, it reduced the doses of analgesics required and their action was strengthened but there was no prolongation of analgesic effects ${ }^{4}$.

Magnesium sulphate as adjunct, parenterally or intraperitoneally improves analgesic efficacy in postoperative period without any unwanted effects ${ }^{2,12}$. Magnesium sulphate is being used as intravenous bolus and continuous infusion, epidural infusion and in subarachnoid space as well and in most of the studies improved the quality of analgesia with fewer requirements of postoperative analgesics ${ }^{9}, 13,14,15$.

We didn't study the blood magnesium sulphate level and sedation score in postoperative ward to conclude the safe level of blood magnesium sulphate level after peritoneal instillation. We only studied the VAS pain score but not shoulder tip pain and other effects like nausea and vomiting. We didn't observe any unwanted effects of study drugs like anaphylaxis, nausea, vomiting and hypotension in the studied patients. Further large scale study is needed to draw definitive conclusion after the use of $50 \mathrm{mg} / \mathrm{kg}$ of magnesium sulphate intraperitoneally for pain management after laparoscopic cholecystectomy.

\section{Conclusion}

Intraperitoneal instillation of $0.25 \%$ bupivacaine not exceeding $2.0 \mathrm{mg} / \mathrm{kg}$ along with $50.0 \mathrm{mg} / \mathrm{kg}$ of magnesium sulphate after completion of laparoscopic surgery renders patients less pain in first 24 hours after surgery, more pain free period and less consumption of tramadol in post-operative period.

\section{References}

1. Hernandez J et al. Intraperitoneal application of bupivacaine plus morphine for pain relief after laparoscopic cholecystectomy. Eur J Anesthesiol. 2003;20(11):891-6.

2. Shoebi $\mathrm{G}$ et al. The additional effect of magnesium sulfate to lidocaine in spinal anesthesia forcesarean section. Int J Pharmacol. 2007;3(5):425-7.

3. Ryu JH, Kang MH, Park KS, Do SH. Effects of magnesium sulphate on intraoperative anesthetic requirements and postoperative analgesia in gynecology patients receiving total intravenous anesthesia. BJA. 2007;100(3):397-403.

4. Edmundas $S$, Rokas L. Use of magnesium sulphate in anesthesiology. Medicina. 2002;38(7).

5. Lee DH, Kwon IC. Magnesium sulphate has beneficial effects as an adjuvant during general anesthesia for caesarean section. BJA. 2009;103(6):861-6.
6. Ray M, Bhattacharjee DP. Effect of clonidine and magnesium sulphate on anesthetic consumption, hemodynamics and postoperative recovery: a comparative study. Indian J Anesth. 2010;54.

7. Abdel-Raouf $\mathrm{M}$, Amer $\mathrm{H}$. Postoperative analgesic effects of intraperitoneal NMDA receptor antagonists (ketamine and magnesium) in patients undergoing laparoscopic cholecystectomy. Engl J Anaesth. 2004;20(2):107-11.

8. Ayoglu $H$, Kradeniz $U$. The analgesic effect of magnesium sulphate and ketamine in patients undergoing laparoscopic cholecystectomy. The Pain Clinic. 2005;17(1):45-53.

9. Mentes O, Harlak A. Effect of intraoperative magnesium sulphate infusion on pain relief after laparoscopic cholecystectomy. Acta Anesthesiol Scand. 2008 Nov; 52(10):1353-9. 
10. Lee I, Kim S, Kong M, Lee M, Kim N, Choi Y, Lim S. Pain after laparoscopic cholecystectomy: the effect and timing of incisional and intraperitoneal bupivacaine. Can J Anaesth. 2001; 48(6):545-50.

11. Tramer MR, Schneider J, Marti RA, Rifat K. Role of magnesium sulfate in postoperative analgesia. Anesthesiology. 1996;84(2):340-7.

12. Dath D, Park AE. Randomized controlled trial of bupivacaine injection to decrease pain after laparoscopic cholecystectomy. JCC. 1999;42(4):2848.

13. Saadwy IM, Kaki AM. Lidocaine vs. magnesium: effect on analgesia after laparoscopic cholecystectomy. Acta Anesthesiol Scand. 2010 May;54(5):549-56.

14. Bhatia A, Kashyap L, Pawar DK, Trikha A. Effect of intraoperative magnesium infusion on perioperative analgesia in open cholecystectomy. J Clin Anesth. 2004;16(4):262-5.
15. Kesavan S. Approapriate timing of administration of magnesium sulphate during spinal anesthesia to enhance postoperative analgesia. BJA. 2010;104(1):89-93.

16. Scheinin B, Kellokumpu I, Lindgren L, Haglund C, Rosenberg PH. Effect of intraperitoneal bupivacaine on pain after laparoscopic cholecystectomy. Acta Anesthesiol Scand. 1995;39(2):195-8.

17. Jiranantarat $V$ et al. Analgesic effect of intraperitoneal instillation of bupivacaine for postoperative pain after laparoscopic cholecystectomy. J Med Assoc Thai. 2002;85 suppl 3:S897-903.

18. Joris J, Thiry E, Paris P, Lamy M. Pain after laparoscopic cholecystectomy: characteristics and effect of intraperitoneal bupivacaine. Anesth Analog. 1995;81:379-84. 